\title{
Why Can An Idea Be Like Nothing But Another Idea? A Conceptual Interpretation of Berkeley's Likeness Principle
}

\section{Introduction}

Berkeley's likeness principle is the claim that "an idea can be like nothing but an idea". There are several reasons for thinking that, amongst the various claims that play a role in his argument for immaterialism, the likeness principle deserves special attention. For one, §8 of the Principles of Human Knowledge, in which it first appears, is a crucial passage when it comes to understanding Berkeley's theory of representation and, more specifically, makes it clear that the mechanism by which Berkeley thinks an idea represents its object is by means of resemblance. It is also remarkable that, despite their objections to idealism and immaterialism, some of Berkeley's best-known critics in the eighteenth- and nineteenth-century, such as Thomas Reid and Mary Shepherd, accepted the likeness principle. 1 One recent commentator has even gone so far as to suggest that "no conclusion in the history of philosophy has been as persuasive" (Jacovides 2009: 417).2

However, the main reason that the likeness principle has attracted so much attention amongst readers of Berkeley's philosophy is that he appears to leave it unargued for. To paraphrase Todd Ryan, Berkeley's treatment of the issue is extremely economic (2006: 580). This is all the more striking when we take into account that the role of the likeness principle is to undermine what was the most widely

\footnotetext{
1 See Reid 1785: 162, Shepherd 1827: 197.

2 The question of why thinkers like Reid and Shepherd accept the likeness principle is an interesting one (although beyond the scope of this paper). Perhaps, like the contemporary 'hard problem' of consciousness, it relates to the fact that the mental and the non-mental, i.e., the physical, seem to be incommensurable. Note, however, that Berkeley himself cannot appeal to this kind of intuition since he does not accept the traditional distinction between the mental and the physical.
} 
accepted theory of knowledge amongst Berkeley's predecessors and contemporaries: representationalism. This is the view that human knowledge of external objects is gained via ideas in the mind which represent them and, most scholars agree, was accepted by Descartes, Malebranche, and Locke.3 Berkeley's point, in PHK §8, is that since an idea can only resemble another idea, and ideas represent by means of resemblance, the claim that ideas represent material objects should be rejected. Berkeley thus provides an argument from the likeness principle, in PHK §8, but does not provide an argument for it.

Berkeley's failure to make it obvious why he accepts the likeness principle has led to several attempts to identify his reasons for accepting it (although at least one commentator has suggested that Berkeley does not explicitly argue for the likeness principle because, "[for him] the proposition was obvious" (Jacovides 2009: 417)). Phillip Cummins (1966), who coined the phrase 'the likeness principle', attributes to Berkeley an argument premised on metaphysical principles about the kinds of entities that can bear a resemblance to one another. Kenneth Winkler (1989) constructs an argument on Berkeley's behalf grounded upon epistemological principles which results in a 'verificationist' reading of the likeness principle. According to Winkler, Berkeley's view is that if we cannot know that two things resemble one another then it is impossible that they ever could. Finally, Todd Ryan argues for a 'new metaphysical interpretation' whereby it is Berkeley's views concerning the metaphysical status of relations that explain his acceptance of the likeness principle. I will say more about each reading in what follows, but I want to draw attention to the fact all of these

\footnotetext{
3 John Yolton argues, across several publications (e.g., 1984 and 1996), against attributing "the standard representative theory" (1984: 113), i.e., representationalism, to the likes of Descartes and Locke. However, I will not engage with this debate here, since I am primarily interested in how Berkeley responds to his opponent's views in light of his reading of them as representationalists.
} 
interpretations entail that Berkeley's reasons for accepting the likeness principle cannot be found in any of his published writings. Cummins derives at least one crucial premise from metaphysical views that Berkeley never articulated in writing because, Cummins claims, he would have taken them to be philosophically commonplace. Both Winkler and Ryan, on the other hand, claim that Berkeley's reasons for accepting the likeness principle can only be found in his Notebooks, which were never intended to be published.

In what follows, I likewise construct an argument for the likeness principle which can, in line with the textual evidence available to us, plausibly be attributed to Berkeley - even if it is not explicit in PHK §8. However, in contrast to previous interpretations, I locate Berkeley's reasons for accepting the premises of that argument in his published writings. This means that on top of explaining why Berkeley accepts the likeness principle, my interpretation identifies a line of reasoning in support of it that was available to Berkeley's readers even before the Notebooks were published.

My contention is that Berkeley accepts the likeness principle on the basis of his account of our conceptual abilities which he develops in the Introduction to the Principles and his views concerning the relation of resemblance espoused in his writings on vision. I attribute to Berkeley the following argument:

Premise 1: There is no intrinsic property of an idea that is not conceived.

Premise 2: For an idea to be like anything but another idea, that idea would need to have at least one intrinsic property that cannot be conceived.

Conclusion: Therefore, an idea cannot be like anything but another idea. 
I derive Premise 1 from the Principles Introduction and argue that Premise 2 is justified by Berkeley's discussion of resemblance relations in the New Theory of Vision and the Theory of Vision Vindicated and Explained.

In section one of this paper, I provide a summary of Cummins', Winkler's, and Ryan's interpretations of Berkeley's reasons for accepting the likeness principle and show that while my reading builds on elements of those interpretations, I place more emphasis on Berkeley's claim that "we shall find it impossible for us to conceive a likeness except only between our ideas" (PHK §8, my emphasis). It will become clear that I take this remark at face value: as a claim about what it is possible for us to conceive. On my reading, Berkeley intends for this claim to justify his acceptance of the likeness principle. Rather than a metaphysical or epistemological interpretation of why Berkeley accepts the likeness principle, I therefore develop a conceptual interpretation: one based on Berkeley's views concerning our conceptual abilities, by which I mean Berkeley's account of what it is and is not possible for us to conceive. In section two, I demonstrate that Berkeley's case against abstract ideas, in the Principles Introduction, commits him to a 'transparency thesis' about the intrinsic properties of our ideas - one which justifies attributing to him Premise 1 of the argument outlined above. In section three, I outline (in 3.1) Berkeley's views concerning likeness relations in his works on vision. I argue that for Berkeley likeness relations are grounded upon the shared intrinsic properties of their relata. I also (in 3.2) justify attributing to Berkeley the claim only ideas have intrinsic properties that can be conceived. In this way, I develop an interpretation of Berkeley's reasons for accepting the likeness principle which, appropriately, focuses on his views concerning ideas and likeness. 


\section{Previous Interpretations of the Likeness Principle}

In this section, I outline three previous interpretations of Berkeley's reasons for accepting the likeness principle: Cummins' 'metaphysical interpretation', Winkler's 'epistemological interpretation', and Ryan's 'new metaphysical interpretation' which focuses on Berkeley's account of the metaphysical status of relations. The aim of this section is to contrast my own 'conceptual interpretation' with those put forward in the literature to date. I will argue that we should focus on Berkeley's claim that "[i]f we look but ever so little into our thoughts, we shall find it impossible to conceive a likeness except only between our ideas" (PHK §8) before explaining why Berkeley thinks the impossibility of conceiving a likeness except only between our ideas justifies the claim that "an idea can be like nothing but an idea" (PHK §8).

Cummins argues that the likeness principle is in fact "shorthand" for three metaphysical claims concerning determinants and determinables. An example of a determinant-determinable relation is the one shared between a shade of colour and colour itself (1966: 64-67). More specifically, Cummins argues that the likeness principle encapsulates three metaphysical claims:

(a) "all qualities which are determinants of the same determinable have the same ontological status";

(b) "a necessary condition of resemblance between two entities is that they are or possess qualities which are determinants of the same determinable";

(c) "none of the qualities we immediately perceive... can occur unperceived".

Cummins has very little to say regarding (a). As he puts it, this claim "is one accepted by anyone engaged in metaphysics or ontology". Any ontological claim that is true of 'red', for example, he claims, will automatically be accepted as true of any other colour. 
This is a minor point, since I do not have any particular issue with attributing this claim to Berkeley, but it is worth noting that Cummins does not clarify whether he thinks that (a) would have been universally accepted amongst Berkeley's contemporaries, or whether this is a claim about those working in metaphysics or ontology more recently. In other words, it is not clear whether this is a historical or a philosophical claim (or both). In any case, I am more interested in (b). Again, I don't see any issue with attributing such a claim to Berkeley. What I take issue with, however, is the way in which Cummins defends his attribution of this claim to Berkeley.

Cummins suggests that (b) is, for Berkeley, "a necessary condition of saying that two things stand in the relation of resemblance" (1963: 65). Despite the somewhat ambiguous phrasing, what Cummins really means is that two things can only be alike if "they are or possess qualities which are determinants of the same determinable". Cummins' ambiguous use of 'saying' here is noteworthy in light of Winkler's 'verificationist' reading of Berkeley's argument. However, elsewhere in his paper, Cummins makes it clear that, on his reading, the likeness principle is a metaphysical principle and not a claim about which things we can know or say are alike, which confirms we should not read too much into the word 'saying' here.

I think Cummins is right to attribute this kind of claim about resemblance to Berkeley. However, I am not convinced that Cummins provides enough textual evidence for us to understand why Berkeley held this view. It is in this sense, in my opinion, that Cummins' interpretation is lacking in comparison with other readings. Admittedly, Cummins does note that there is evidence that Berkeley thinks only determinants of the same determinable can resemble one another, such as the claim that "a colour or figure can be like nothing but another colour or figure" (PHK §8). But there is no textual explanation forthcoming for why Berkeley took this to be the case 
or why Berkeley thought his readers ought to too.4 One advantage of my interpretation, and particularly the case I build in section three, is that I do identify Berkeley's reasons for accepting (b), or something like it.

In contrast to Cummins' 'metaphysical interpretation', Winkler develops an 'epistemological interpretation' of the likeness principle. Instead of trying to extract an argument for the likeness principle from $\S 8$ of the Principles, or identify metaphysical principles that Berkeley is implicitly committed to in his published works, Winkler focuses on entry 378 of Berkeley's Notebooks. While, as he sees it, Berkeley's "only published defence of the likeness principle" (1989: 146, my emphasis) is the dilemma he presents his opponents with in the second half of Principles $\S 8,5$ it is this notebook entry that explains why he accepts it. The argument in NB 378 that Winkler has in mind rests on the premise that "[t]wo things cannot be said to be alike or unlike till they have been compar'd" along with Berkeley's characterisation of comparison as "the viewing two ideas together, \& marking [what] they agree in \& [what] they disagree in". Since "the mind can compare nothing but its' own ideas", the argument in the Notebooks concludes that "[n]othing like an idea can be in an unperceiving thing." As Winkler notes, this conclusion can only be reached if we read Berkeley as holding the verificationist principle that "if it is impossible to find out that two things are alike, they cannot be said to be alike" (1989: 147).

Winkler's interpretation is more successful than Cummins' in helping us to understand why Berkeley accepts the likeness principle. In fact, we have strong textual

\footnotetext{
4 Similarly, Winkler argues that Cummins' interpretation ultimately "fails as an explanation of why Berkeley embraces the likeness principle" (1989: 145, my emphasis).

5 The dilemma is as follows: "I ask whether those supposed originals or external things, of which our ideas are the pictures or representations, be themselves perceivable or no? If they are, then they are ideas, and we have gained our point; but if you say they are not, I appeal to anyone whether it be sense, to assert a colour is like something which is invisible; hard or soft, like something which is intangible; and so of the rest.” (PHK §8)
} 
evidence that this was Berkeley's argument for something very close to the likeness principle when we was writing the Notebooks. Yet, I suggest there are at least two reasons for thinking that the argument in NB 378 is not Berkeley's final word on the matter. First, Winkler's reading implies that, despite having formulated at least one specific argument for the likeness principle, Berkeley later decided not to present that argument to his readers or make any of his views about comparison available to his readers upon the publication of the Principles. This raises the question why, if Berkeley developed an argument for the likeness principle, he didn't make that argument available to his readers. Winkler leaves this question unanswered. Second, Berkeley does not mention comparison in any passages that serve to defend or justify the likeness principle in either the Principles or the Three Dialogues.6 As Ryan notes, "Winkler provides no positive textual evidence [for his reading of Berkeley] apart from the argument at [NB] 378" (2006: 574).

However, as Winkler himself acknowledges, Berkeley does support his acceptance of the likeness principle, in his published texts, by reference to claims about what it is possible to conceive. It should be clear by now that I think Berkeley's remark that "we shall find it impossible to conceive a likeness except only between our ideas" is significant. Winkler does too, but only because he reads it as an allusion to the comparison argument in NB 378.

I think it is certainly plausible to read this as an allusion to NB 378 (indeed, I think it is plausible to suggest that Berkeley continued to think the role of comparison was important. But the question still remains why Berkeley does not discuss

\footnotetext{
6 In PHK §104, Berkeley does claim that a comparison of two phenomena will allow us to "observe some likeness and conformity between them" but this does not appear to be a remark about what ideas can and cannot resemble. The term 'compare' does not appear even once in the Three Dialogues. The term 'comparison' is used, but in a way that seems much closer to 'analogy' or 'metaphor'.
} 
comparison explicitly in his published works.) However, if Winkler is right, it raises the question why Berkeley ultimately decided to make a claim about what it is possible for us to conceive rather that what we can compare and, perhaps more pressingly, why there is no discussion of comparison in Berkeley's published works. Without explaining why Berkeley refers to claims about what it is possible to conceive, we cannot be said to have provided an explanation for why he accepts the likeness principle as it is presented in his published works - which, I take it, is what we are trying to do.

Ryan also situates Berkeley's argument for the likeness principle in NB 378. However, he rejects Winkler's epistemological reading in favour of a 'new metaphysical interpretation' (2006: 574). One feature of Ryan's interpretation that sets it apart from its predecessors is Ryan's claim that NB 378 contains two arguments for the likeness principle - which, he points out, is corroborated by Berkeley's note that "[t]hese arguments must be proposed shorter \& more separate in the Treatise" (NB 378a).7 The first such argument is roughly consistent with Cummins' reading and rests on the premise that only things which are of the same kind can resemble one another. But Ryan does not think that this was the argument Berkeley accepted when he published the Principles. Rather, Ryan argues, Berkeley's mature argument for the likeness principle concerns the metaphysical status of relations.

Ryan attributes to Berkeley the same account of relations that he identifies in Locke, namely, that all relations are mind-dependent. This is supported by Berkeley's claim in the Principles that "all relations including an act of the mind, we cannot so properly be said to have an idea, but rather a notion, of the relations or habitudes

\footnotetext{
7 The conclusion of both arguments is that "nothing like an idea can be in an unperceiving thing", a claim which appears twice in NB 378. This indicates that the aim of the likeness principle is to undermine representationalism, rather than restrict likeness relations to ideas. This is significant since, as I discuss in my conclusion, Ryan's reading implies that only ideas can resemble one another.
} 
between things" (PHK §142). As Ryan reads it, Berkeley's argument for the likeness principle follows like so:

If resemblance is taken to be a relation between two objects, and if relations essentially involve a mental act of comparison, then a necessary condition of two things resembling one another is that they either are or have been the objects of a mental act of comparison. (2006: 575)

Since the only possible objects of a mental act of comparison are ideas, ideas are the only possible relata in the relation of resemblance. If Ryan's interpretation is accurate then Berkeley accepts the likeness principle because of his views on comparison.

I think Ryan is right that his reading makes "significant progress" in our understanding of the likeness principle (2006:580). Berkeley certainly does appear to have started off with two distinct arguments, and the question of what changed prior to the publication of the Principles needs addressing. Yet, the fact of the matter is that Berkeley never attempts to justify or defend his acceptance of the likeness principle by appealing to claims about comparison in any of his published writing. In fact, there is no sustained discussion of comparison in the Principles or the Three Dialogues at all. This means that, if Ryan (or Winkler) is right, then without the Notebooks we could not possibly understand why Berkeley accepts the likeness principle.

However, Berkeley does make it clear to his readers how important it is that we pay attention to what it is possible for us to conceive. I've referred to Berkeley's claim in the Principles that it is "impossible for us to conceive a likeness except only between our ideas" several times (PHK §8). But it is also worth considering the following exchange in the Three Dialogues: 
Phil. But how can that which is sensible be like that which is insensible? Can a real thing in itself invisible be like a colour, or a real thing which is not audible be like a sound? In a word, can anything be like a sensation or idea, but another sensation or idea?

Hylas. I must own, I think not.

Phil. Is it possible there should be any doubt in the point? Do you not perfectly know your own ideas?

Hylas. I know them perfectly; since what I do not perceive or know, can be no part of my idea.

Phil. Consider therefore, and examine them, and then tell me if there be any thing in them which can exist without the mind: or if you can conceive of any thing like them existing without the mind.

Hylas. Upon inquiry, I find it is impossible for me to conceive or understand how any thing but an idea can be like an idea. (DHP 206)

Here, Berkeley introduces some similar claims to those in Principles $\S 8$, but he also ties them explicitly to the knowledge that we have of our ideas and to what it is possible for us to conceive. I think Ryan is probably right that while composing the Notebooks it was Berkeley's views on comparison that motivated his acceptance of the likeness principle. However, the textual evidence suggests that by the time he was writing the Principles and the Three Dialogues, it is the somewhat separate issue of what it is possible for us to conceive that plays this role. For that reason, I develop a conceptual interpretation of Berkeley's reasons for accepting the likeness principle in what follows. 


\section{Ideas in the Introduction to the Principles}

\subsection{The existence of ideas as transparent}

In this section, I will demonstrate that in the Introduction to the Principles Berkeley develops an account of our conceptual abilities which commits him to two principles. First, that for an idea to exist it must be conceived. Second, that the intrinsic properties of an idea are transparent to the subject conceiving it. Together, these principles justify attributing to Berkeley Premise 1 of the argument outlined in my introduction: there is no intrinsic property of an idea that is not conceived.

In the Principles Introduction, Berkeley offers at least three reasons to reject the existence of abstract ideas. First, he argues that they are superfluous to explanation. Locke, who is Berkeley's primary target, infers from the meaningfulness of general terms in language (such as the word 'red') that we must have abstract general ideas (such as the idea of redness). This is based on the semantic principle that words "stand as outward marks of our internal ideas" (EHU 2.6.9).8 However, Berkeley argues that the meaningfulness of general terms is actually down to the fact that arbitrarily chosen particular ideas become general simply by "stand[ing] for all other particular ideas of the same sort." (PI §12) Second, Berkeley argues that abstract ideas would have to possess inconsistent properties and thus rejects them on the grounds that an inconsistent entity cannot possibly exist, even in the mind. For example, he cites Locke's description of an abstract general triangle as one which "must be neither oblique nor rectangle, neither equilateral, equicrural, nor scalenon, but all and none of these at once" (EHU 4.7.9/ PI §13). Locke admits that such an

8 There is much scholarly debate, which I bypass here, about whether Berkeley rejects Locke's theory of meaning. For a comprehensive survey of such literature, see Pearce (forthcoming). 
entity is "something imperfect, that cannot exist" - Berkeley's view is that it could not exist in the mind either (PHK §5). Finally, Berkeley supports his rejection of abstract ideas by appealing to the introspective evidence on offer to him. It is this aspect of Berkeley's anti-abstractionism that is of most relevance to my present concerns.

Berkeley's view is that it is simply impossible to conceive of abstract ideas. For example, he writes:

Whether others have this wonderful faculty of abstracting their ideas, they best can tell; for my self I find indeed I have a faculty of imagining, or representing to my self the ideas of those particular things I have perceived and of variously compounding and dividing them. (PI §10)

Berkeley's point is clearly rhetorical: he is convinced that it is impossible for anyone to conceive an abstract idea. Alongside bolstering the case against abstract ideas, this passage also makes it clear which ideas Berkeley thinks it is possible for us to conceive. He identifies the following three types of idea as conceivable:9

(i) Ideas which represent those things I have perceived via the senses.

(ii) Ideas that result from compounding or putting together ideas of type (i).

(iii) Ideas that result from dividing ideas of type (i).

Ideas of type (i), ideas of memory, cannot be abstract since they are copies of things I have perceived via the senses and those things are not abstract (see PHK §5). Ideas of type (ii) and (iii) are both ideas of the imagination. Again, in both cases, whatever is conceived must have a particular shape and colour along with any other quality the

\footnotetext{
9 Berkeley's treatment of ideas in the Principles Introduction is complicated by the fact that he is hesitant to reveal that he thinks even real things - i.e., things we perceive via the senses - are also ideas until the body of the text. This is because, as he explains in a letter to his friend Percival, he wanted the notion of immaterialism to "steal unawares" on his readers (Hight 2013: 44). Consequently, when he gives a taxonomy of ideas in this passage, he does not include ideas of sensation (i.e., 'real things' (PHK §33)).
} 
ideas possess, since these imagined ideas are put together or separated from ideas which are themselves particular.

Berkeley's reasoning reveals that he is committed to the claim that for an idea to exist, it must be conceived. Since abstract ideas cannot be conceived, he argues, it therefore follows that abstract ideas do not exist. This indicates that Berkeley accepts a 'transparency thesis' regarding our ideas. In the words of Martha Brandt Bolton, Berkeley believes that "an idea is fully accessible to the mind that has it" (1987: 69). I consider the scope of this transparency thesis in the next sub-section.

\subsection{The intrinsic properties of ideas as transparent}

So far, I have argued that in the Principles Introduction, Berkeley commits himself to an important principle concerning the existence of ideas:

(i) For an idea to exist, it must be conceived.10

However, my contention is that the theory of ideas developed in the Principles Introduction also entails that the intrinsic properties - and not just the existence - of an idea are transparent to a perceiver. Before proceeding, it is worth clarifying what exactly I mean by this. We can attribute intrinsic and extrinsic properties to an object. We can say of a post box, for example, that it is green, solid, a certain cylindrical shape, and so on. These are the post box's intrinsic properties. We can also say of the post box that it is on Nassau Street, that it is taller than the post box on O'Connell street, and that it is approximately one-hundred metres from where I am currently

\footnotetext{
10 Note that this is not the same as saying that for anything to exist it must be conceivable. Pappas, Rickless, and Winkler think Berkeley does hold, that if something is inconceivable, then it is impossible. Ott and Holden both argue that Berkeley explicitly rejects this principle (citing, e.g., PHK $\S 81$ and DHP 232-33). See Pappas 1995, Rickless 2013: 112, 132, 181-82, Winkler 1989: 30-31, Ott 2015, Holden 2019.
} 
located. These are extrinsic properties of the post box. They concern how the post box is related to other things (like me, the post box on O'Connell street, and the rest of the city). My claim is that, for Berkeley, the intrinsic properties of an idea - and not its extrinsic properties - are transparent to a perceiver.

This distinction is important because the extrinsic properties of an object depend on the relations it bears to other things and Berkeley does not think relations are immediately (or transparently) known along with their relata. In the 1734 revised edition of the Principles, Berkeley maintains that the relations ideas bear to one another need not be immediately perceived, even when the ideas themselves are. He writes:

we know and have a notion of relations between things or ideas, which relations are distinct from the ideas or things related, inasmuch as the latter may be perceived by us without our perceiving the former. (PHK §89)

Berkeley's claim is that relations between ideas are distinct from the ideas themselves and that it is possible to perceive ideas without being aware of the relations between them.11 For example, I might be familiar with both the post box on Nassau Street and the post box on O'Connell street without being aware of how far away from one another they are.12 It's important to note that my contention is that Berkeley thinks the intrinsic properties of an idea are transparent to a perceiver.

In the Principles Introduction, Berkeley claims if we consider our ideas "bare and naked" and keep out of our thoughts words or names which we have come to

\footnotetext{
11 Berkeley also maintains that ideas and relations are heterogenous entities. Ideas, he claims, are passive entities which exist by being perceived (PHK §25). Relations, on the other hand, include "an act of the mind" (PHK §142). For that reason, he explains - just as in the case of spirits (PHK \$27) - "we cannot properly be said to have an idea, but rather a notion, of the relations or habitudes between things" (PHK §142).

12 For more on Berkeley’s view that distance is not immediately perceived, see, e.g., NTV §§1-3.
} 
associate with them due to "constant use", we will find that there are three benefits (PI §21). First, we will avoid "controversies purely verbal". Second, we will avoid looking for abstract ideas "where there are none to be had" (PI §24). Third, he explains:

so long as I confine my thoughts to my own ideas divested of words, I do not see how I can easily be mistaken. The objects I consider I clearly and adequately know. I cannot be deceived in thinking I have an idea which I have not. It is not possible for me to think, any of my own ideas are alike or unlike which are not truly so. To discern the agreements and disagreements there are between my ideas, to see what simple ideas are included in any compound idea,13 and what not, there is nothing requisite but an attentive perception of what passes in my own understanding. (PI §22)

This passage reveals that Berkeley is concerned with more than just the existence of our ideas: he also thinks there is an important connection between our conceptual abilities and resemblance relations. One of the upshots of this passage is that if I cannot conceive a resemblance relation between two (or more) ideas, then such a relation cannot exist. For, as he puts it, "[i]t is not possible for me to think, any of my ideas are alike or unlike which are not truly so." Likewise, if I do conceive of such a resemblance relation, then I can know with certainty that the ideas in question are alike.

It seems remarkable to me that neither Winkler nor Ryan pick up on this passage as it is surely the closest Berkeley comes to talking about comparison in the Principles. Here, we learn that, according to Berkeley, it is impossible to think that

\footnotetext{
13 Berkeley does not talk of 'compound ideas' in the body of the Principles but rather 'collections of ideas' (as in PHK §1). This is another instance in which Berkeley is hiding the extent of his break with contemporary views in the Introduction so that his own view will "steal unawares" on the reader (see Hight 2013: 44). Here, for example, he appears to align himself with Locke's account of simple and compound ideas.
} 
ideas are alike or unalike unless they really are alike or unalike. We also learn that all I have to do to discern whether my ideas agree or disagree with one another is pay attention to "what passes in my own understanding" - in other words, what I am conceiving. But Berkeley does not use any of the language of comparison from the Notebooks here. Instead, he presents his view as a set of claims about what it is possible for us to conceive. I suggest that this is strong evidence that prior to writing the Principles, Berkeley made the decision to re-package his views on comparison in terms of our conceptual abilities. This need not entail that Berkeley rejects the role of comparison entirely; it seems plausible that "discern[ing] the agreements and disagreements there are between my ideas" involves the kind of mental comparison Berkeley describes in NB 378. Nonetheless, the fact still remains that Berkeley decided, prior to publishing the Principles, not to present this claim in terms of conception and not comparison.

Along with his repeated encouragement to reflect on our ideas "bare and naked", "divested of words", "undisguised", and to "obtain a clear view of the ideas [we] consider" (PI §§21-25), I think the passage above justifies attributing to Berkeley a second claim:

(ii) The intrinsic properties of an idea are transparent to the subject conceiving it. 14

For further evidence that Berkeley accepts this claim, it is possible to identify instances where it is explicitly put to work in the body of the Principles. For example, in §25 Berkeley defends the claim that ideas are passive entities by claiming that "[t]o be

\footnotetext{
14 For a similar claim, see Rickless 2013: 42. Rickless attributes to Berkeley the claims that "it is a fundamental truth that when a sensation is directly and wholly present to the mind, there is nothing in the sensation that could possibly be hidden to the mind" and that "the mind cannot make a mistake about what the sensation is like". See also Dicker 2011: 33.
} 
satisfied of the truth of this, there is nothing else requisite but a bare observation of our ideas". Notice the emphasis, familiar from the Introduction, on bare observation. He then puts forward the following argument:

For since they and every part of them exist only in the mind, it follows that there is nothing in them but what is perceived. But whoever shall attend to his ideas, whether of sense or reflexion, will not perceive in them any power or activity; there is therefore no such thing contained in them. (PHK §25) 15

The first premise of this argument, that there is nothing in our ideas but what is perceived, is precisely what Berkeley establishes in the Introduction and puts to work in his case against abstract ideas. Phillip Cummins calls this premise the 'Manifest Qualities Thesis' and characterises it as the view that "sensibles [or ideas] have only those qualities they are perceived to have" (1990: 387) 16 As Cummins notes, Berkeley's claim in PHK $§ 25$ is that since we do not perceive in our ideas any power or activity, we can conclude that there is no power or activity contained in them. It is clear, therefore, that Berkeley subscribes to the view that if a property is not perceived to be in an idea, then that property is not an intrinsic property of that idea. For this reason, we can plausibly attribute to Berkeley the view that the intrinsic properties of an idea are transparent to a perceiver.

In summary, I have argued that we can attribute two principles to Berkeley:

15 For a similar line of argument, see PHK 87: “[c]olour, figure, motion, extension and the like, considered only as so many sensations in the mind, are perfectly known, there being nothing in them which is not perceived." This is reiterated in the Three Dialogues (DHP 206). The general form of both arguments is:

$\mathrm{P} 1$. There is nothing in our ideas that is not perceived.

$\mathrm{P} 2 . \mathrm{X}$ is not perceived in our ideas.

C. Therefore, $\mathrm{X}$ is not in our ideas.

16 One of Cummins' central aims in this paper is to determine why Berkeley accepts the Manifest Qualities Thesis (MQT). I defer to Cummins' explanation in this instance, since my aim is understanding why Berkeley accepts the likeness principle. It is enough, for my purposes, to establish that Berkeley does indeed accept MQT and that it is at work in the Principles Introduction, which should now be evident. 
(i) For an idea to exist, it must be conceived.

And:

(ii) The intrinsic properties of an idea are transparent to the subject conceiving it.

Cummins attributes virtually the same pair of transparency claims to Berkeley (1990: 391-92). The question is, then, how do these transparency claims justify Berkeley's employment of the likeness principle? In the next section, I will argue that, as Berkeley sees it, reflecting on the intrinsic properties of our ideas informs us that "an idea can be like nothing but an idea". The reason being that a resemblance relation is grounded on the intrinsic properties of ideas, which are, as (ii) entails, transparently known. Returning to the question of why Berkeley accepts the likeness principle, it is for this reason, I contend, that he appeals to the fact that "[i]f we look but ever so little into our thoughts, we shall find it impossible to conceive a likeness except only between our ideas" (PHK §8).

\section{Likeness Relations and Intrinsic Properties}

\subsection{Identity in nature}

The aim of this section is to justify attributing to Berkeley Premise 2: for an idea to be like anything but an idea, that idea would need to have at least one intrinsic property that cannot be conceived. I have argued that Berkeley accepts the likeness principle on the basis of this premise in conjunction with Premise 1: there is no intrinsic property of an idea that is not conceived. Together, these premises entail that "an idea can be 
like nothing but an idea" (PHK §8). In this subsection, I will argue that, for Berkeley, resemblance between two (or more) objects involves their having intrinsic properties in common, drawing textual evidence from his works on vision. In 3.2, I will justify attributing to Berkeley the view that only ideas have intrinsic properties that can be conceived. It follows from these claims that since anything that is not an idea would possess intrinsic properties that cannot be conceived, for an idea to resemble a nonidea it would also need to have at least one intrinsic property that cannot be conceived.

In the New Theory of Vision and the Theory of Vision Vindicated and Explained, Berkeley uses the phrase "identity of nature" to refer to a property that two objects have in common and which makes them alike. This phrase is used sparingly (in NTV §147, TVV §47, and TVV §52) but is significant because it reveals that Berkeley thinks likeness relations are grounded in the intrinsic properties of their relata. NTV $\S 147$ is an important passage in Berkeley's corpus because it is his first articulation of the Divine Language Hypothesis, his view that God speaks to us via the language of vision and informs us how to act so that we can "attain those things that are necessary to the preservation and well-being of our bodies" and "avoid whatever may be hurtful and destructive of them". Towards the end of this section, Berkeley clarifies that, just as with any other language, the connection between the 'words' (our visual ideas) and their significations (tactile ideas of pleasure and pain) is not necessary but "habitual". More specifically, he explains that our visual ideas do not signify tactile ideas "by any likeness or identity of nature". In other words, there is nothing in common between an object of sight and an object of touch; they are, for Berkeley, entirely unalike (or heterogenous).

Similarly, in TVV §47, Berkeley claims that when we mistakenly assume that the objects of vision and touch are homogenous, as a result of the constant 
conjunctions we experience between the two, we "suppose an identity of nature, or one and the same object common to both senses". That is, we suppose that we can see and feel one and the same sensible object - a supposition which Berkeley rejects. For example, I might (mistakenly, Berkeley thinks) claim to 'see' the sharp corner of a cube because objects which are shaped in a certain way have always been accompanied by a tactile sensation of sharpness.

I suggest that these passages provide strong evidence that for two (or more) objects to have an identity of nature is, for Berkeley, for them to have at least one intrinsic property in common. If, for example, the visual corner of the desk which I see before me and the tangible corner which I can reach out and touch with my hands really did possess the same property of 'sharpness' then it would follow that, in accordance with Berkeley's use of the phrase, those two objects do have an identity of nature. But they do not, Berkeley argues, and hence we should conclude that they are entirely heterogenous objects.

What does this mean for likeness relations? It indicates that likeness relations, unlike other relations between objects in Berkeley's system, are grounded upon the shared intrinsic properties of their relata. For this reason, Michael Jacovides is right to call resemblance the "non-arbitrary backbone of Berkeley's theory of representation" (2009: 418) and, in terms of Berkeley's wider theory of intentionality, it makes for the difference between ideas that represent one another and those which arbitrarily signify in the same way that words conventionally signify their meanings. In short, two things must have at least one intrinsic property in common for them to resemble (and thereby 
represent) one another. This makes likeness relations unique since they, unlike other relations, must be grounded on an identity of nature.17

We've seen already that in $\S 89$ of the Principles, Berkeley claims that we can perceive two (or more) relata without perceiving the relations between them. For example, I might perceive the post box on Nassau Street and the post box on O'Connell Street, without perceiving the distance at which they stand from one another. But I suggest that Berkeley's account of what grounds likeness relations should encourage us to re-think this passage. We know, from the Principles Introduction and the discussion in section two, that Berkeley thinks the intrinsic properties of an idea are transparent to a perceiver. But PHK $\S 89$ tells us our knowledge of relations between ideas is distinct from our knowledge of the ideas themselves. We can infer from this that there is nothing about the intrinsic properties of an idea that informs us about the relations it stands in. However, we also now know, from an examination of the relevant sections in the works on vision, that this is not the case when it comes to likeness relations. Likeness relations are grounded on the intrinsic properties of their relata and, what's more, Berkeley thinks that those things which resemble one another share an identity of nature. This sets likeness relations apart from other relations.

It is true that Berkeley thinks all relations include an act of the mind (PHK §142), but there is a genuine sense in which while other relations, such as the distances between things, are constituted by our perceiving them, likeness relations are there to

\footnotetext{
17 It was pointed out to me by Manuel Fasko that other relations, such as one object's being taller than another, are also dependent on the intrinsic properties of their relata (i.e., each objects' height). But this would not constitute an 'identity of nature' since those objects would not have an intrinsic property in common. If the two objects were the same height, the case would be different, since this would count as an instance of a resemblance relation.
} 
be discovered. ${ }_{18}$ Crucially, they are not 'habitual' or based on past experience. This is because likeness relations, uniquely, can only hold between two (or more) objects which share an identity of nature: shared intrinsic properties.

There is plenty of textual support, in the works on vision, for attributing to Berkeley a distinction between likeness relations - which he describes as "natural" (NTV §144) - and those which are the result of the "habitual connexions" we observe between things. In TVV $§ 20$, for example, he contrasts those ideas which share a "likeness of nature" with those whose relations are grounded "merely in experience and custom". For that reason, I do not think we should read Berkeley's claim in Principles $\S 89$ as axiomatic and intended to apply to all relations whatsoever. Rather, we should take it to apply only to those relations (which, admittedly, is the majority of them) which are not grounded on an identity of nature.

\subsection{Concerns about conceivability}

Finally, to justify attributing to Berkeley Premise 2 (for an idea to be like anything but an idea, that idea would need to have at least one intrinsic property that cannot be conceived), it remains to be shown that he thinks only ideas have intrinsic properties that can be conceived. To alleviate potential concerns about the conceivability of minds, I will show that if Berkeley thinks minds are also conceived then it is in a very different, 'looser' sense. For my purposes, it is enough that Berkley thinks only ideas have intrinsic properties that are conceived in a strict sense.

\footnotetext{
18 Wilfred Sellars claims that, for Berkeley, resemblances between things are given in perception (1997: 62-63). An anonymous reviewer pointed out that my reading does not commit Berkeley to such a strong view and is consistent with the observation that often some kind of attention, reflection, or comparison is required to become aware that two things resemble one another.
} 
One might be concerned that my reading of Berkeley renders minds (the other half of Berkeley's ontology) inconceivable. If ideas are the only entities which have conceivable intrinsic properties, and assuming that an entity without any conceivable intrinsic properties cannot itself be conceived, then minds cannot be conceived. As a reviewer pointed out, this seems to conflict with PHK $\S 140$ where Berkeley writes:

as we conceive the ideas that are in the minds of other spirits by means of our own, which we suppose to be resemblances of them, so we know other spirits by means of our own soul, which in that sense is the image or idea of them (my emphasis)

Berkeley's point is that we gain knowledge of other minds by reflecting on our own mind, which we take to resemble them, in the same way we gain knowledge of other peoples' ideas by reflecting on our own ideas. This passage might present a problem for my reading, since it could be suggested that Berkeley thinks we conceive other minds similarly to how we conceive other peoples' ideas.

However, I do not think the textual evidence supports this reading of PHK $\S 140$. In fact, the textual evidence indicates that Berkeley thinks the term 'conceive' - if it can be applied to minds - means something very different to when it is applied to ideas. In PHK §142 Berkeley explains that, "[s]pirits and ideas are things so wholly different that when we say 'they exist', 'they are known', or the like, these words must not be thought to signify anything common between both natures" (my emphasis). If minds are known in an entirely different way to how we conceive our ideas, then this either suggests that they are not conceived or that the term 'conceive' means something very different when applied to minds. 
This is borne out in Berkeley's remark, in the same section, that: "I have some knowledge or notion of my mind, and its acts about ideas, inasmuch as I know or understand what is meant by those words." Again, this indicates that conceiving minds involves something very different to conceiving ideas. Recall, for example, Berkeley's claim in the Principles Introduction that we ought to "draw the curtain of words" in order to conceive our ideas "bare and naked" (PI §§21-24). Conceiving ideas, Berkeley maintains, involves freeing ourselves of our linguistic associations with them. Conceiving minds (if indeed they are conceived), on the other hand, seems to be closely tied up with how we refer to them in language.

PHK §5 provides further evidence that Berkeley does not think we conceive ideas in the same way we conceive minds. There, Berkeley claims that "my conceiving or imagining power does not extend beyond the possibility of real existence or perception". In this instance, Berkeley is using 'conceive' in a strict sense applicable only to ideas. Note that he equates conceiving with imagining. If conceiving just is imagining, for Berkeley, then we can only conceive of things which could, in principle, be perceived - since he thinks ideas of imagination are ideas of things which "may really exist or be actually perceived" (PHK §5). Minds and their activities could never in principle be perceived (PHK §27); thus, if we take Berkeley at his word, minds and their activities cannot be conceived (at least in the relevant sense in this passage) either. They lie beyond "my conceiving or imagining power". Again, this indicates that 
if Berkeley thinks minds can be conceived, then it is not in this strict sense and involves something very different to conceiving ideas.19

PHK $\S 5$ might also give rise to a related question: does Berkeley think that inconceivability entails impossibility? If so, we cannot plausibly attribute to him the view that minds are inconceivable. But the textual evidence does not justify attributing to Berkeley such a strong account of the relation between inconceivability and impossibility. What PHK $\S 5$ does commit Berkeley to is the restricted claim that if a sensible thing (something of which it can be said, its esse is percipi (PHK §3)) cannot be conceived, then it could not possibly exist.20 However, minds are not sensible things (their esse is percipere, not percipi (NB 49)) so their inconceivability (in a strict sense of the term) does not entail their impossibility. 21

We are now in a position to understand why it is appropriate to attribute to Berkeley Premise 2. Berkeley's account of resemblance tells us that for two (or more) things to resemble one another, those things must share at least one intrinsic property. For a likeness relation can only be grounded on such an "identity of nature". As Berkeley understands it, only ideas have intrinsic properties that can be conceived.

\footnotetext{
19 A reviewer raised the question why we should think Berkeley's distinction between two kinds of conceivability is more basic than his commitment to the likeness principle. I think Berkeley took it to be a simple fact of the matter, introspectively verifiable, that we cannot conceive minds in the strict sense of the term (whereby it is synonymous with 'imagine'). However, Berkeley's attempts to defend (in PHK §8) and argue for (in NB 378) the likeness principle suggest he saw it as something in need of justification in one way or another.

20 See Holden 2019 for an in-depth discussion of Berkeley's views on inconceivability and impossibility.

21 An anonymous reviewer raised the further concern that, by accepting that only the intrinsic properties of ideas can be conceived, Berkeley begs the question against representationalists. This concern would bear out if Berkeley were combatting a view that included a commitment to the claim that the intrinsic properties of material objects are also conceivable. The textual evidence, however, suggests that this is not the view that Berkeley took himself to be opposing. Rather, at least as Berkeley understands his opponents, their view is that we gain knowledge of mind-independent material objects via those things (namely, ideas) which are conceivable. In other words, Berkeley takes himself to be on the same page as his opponents when it comes to what is conceivable (see, e.g., DHP 262). The difference, as Berkeley understands it, is that his opponents are committed to the additional claim that as well as ideas, there are "archetypes existing without the mind" (PHK §87). One might respond, on behalf of the representationalist, that those archetypes are mediately conceived via our immediately conceived ideas. But Berkeley's reply is likely to be that this pre-supposes a resemblance between ideas and archetypes, which is precisely the question at hand. Of course, there remains the further question of whether Berkeley accurately characterises his opponents, but this is beyond the scope of this paper.
} 
Thus, for an idea to be like anything but another idea, that idea would have to have at least one intrinsic property that cannot be conceived. We now know, from the Principles Introduction and the discussion in section two, that Berkeley does not think this is possible.

\section{Conclusion: Conceiving a Likeness}

I have argued that to understand Berkeley's reasons for thinking that "an idea can be like nothing but an idea" we need to focus on the claim that, "[i]f we look but ever so little into our thoughts, we shall find it impossible to conceive a likeness except only between our ideas" (PHK §8). My approach has been to work out why Berkeley took this claim about conceiving a likeness to be enough to justify his employment of the likeness principle.

What exactly does it mean to 'conceive a likeness'? If Winkler and Ryan are right, and Berkeley accepts the likeness principle on the back of the argument in NB 378 , then to conceive a likeness would be to compare two ideas and note that they "agree" in a certain way. One of the implications of this reading, as Ryan acknowledges, is that since "[t]he mind can compare nothing but its' own ideas", and since the only things which can be said to be alike are things which have been compared, it seems to follow that only ideas can resemble one another. Ryan is careful to explain that "although Berkeley formulates his argument in terms of ideas, what is really at issue are the immediate objects of awareness" (2006: 578). So what Ryan thinks follows is that only the immediate objects of awareness can be alike; he intends for this to allow for likenesses between volitions. It's worth noting that my reading does

not commit Berkeley to such a restrictive account of resemblance. To conceive a 
likeness, on my reading, is to conceive the intrinsic properties that make two things alike - their 'identity of nature'. Berkeley's view is that since all the intrinsic properties that we can conceive (in a strict sense) belong to ideas, the only kind of likeness we can conceive is between two (or more) ideas. But that does not mean that likeness itself can only hold between ideas. For likeness relations are grounded on shared intrinsic properties ('identities of nature') and ideas are not be the only entities with intrinsic properties in Berkeley's system - minds, for example, could be alike.

We are now, finally, in a position to appreciate why Berkeley accepts the likeness principle as it is presented to us in his published works. The evidence that Berkeley at one point accepted the likeness principle on the basis of the comparison argument(s) in the Notebooks is convincing. But any such reasoning is absent in both the Principles and the Three Dialogues. Instead, in both texts, Berkeley appeals to the impossibility of conceiving a likeness between anything but our ideas. Having followed this important clue as to what Berkeley's reasoning involves, I have shown that we can construct an argument on Berkeley's behalf that is premised on his account of our conceptual abilities in the Principles Introduction and his account of resemblance in the works on vision. If we conceive of a likeness between two things, then we know that what makes them alike - their identity of nature - is their having at least one intrinsic property in common. But Berkeley thinks it is impossible for an idea to share an intrinsic property with a non-idea - something that (he thinks) is made evident by the fact that "it is impossible for us to conceive a likeness except only between our ideas". It is on the basis of this conceptual evidence, then, that Berkeley accepts that "an idea can be like nothing but an idea'”.22

22 Thanks to Kenny Pearce, Manuel Fasko, Katia Saporiti, Peter Kail, and several anonymous reviewers for providing constructive feedback on versions this paper. 


\section{Bibliography:}

Primary sources (with abbreviations):

Berkeley, George. (2008)'A Treatise Concerning the Principles of Human Knowledge'. In Desmond Clarke (ed.), Philosophical Writings (Cambridge: Cambridge University Press), pp. 67-149. References are to section number in that edition. (PHK for the body of the text, PI for the Introduction.)

Berkeley, George. (2008) 'An Essay Towards a New Theory of Vision'. In Desmond Clarke (ed.), Philosophical Writings (Cambridge: Cambridge University Press), pp. 166. References are to section number in that edition. (NTV)

Berkeley, George. (1989) Philosophical Commentaries. George Hasson Thomas (ed.) (Ohio: Garland). References are to entry number in that edition. (NB)

Berkeley, George. (2008) 'The Theory of Vision, or Visual Language, Shewing the Immediate Presence and Providence of a Deity, Vindicated and Explained'. In Michael Ayers (ed), Philosophical Works Including the Works on Vision (London: J. M. Dent), pp. 277-304. References are to section number in that edition. (TVV)

Berkeley, George. (2008) 'Three Dialogues Between Hylas and Philonous'. In Desmond Clarke (ed.), Philosophical Writings (Cambridge: Cambridge University Press), pp. 151-242. References are to marginal numbers in that edition. (DHP)

Locke, John. (1975) An Essay Concerning Human Understanding. Peter H. Nidditch (ed.), Oxford: Oxford University Press. References are to book number, chapter number, section number in that edition. (EHU)

Reid, Thomas. (1785) Essays on the Intellectual Powers of Man. London: John Bell. 
Shepherd, Mary. (1827) Essays on the Perception of an External Univerise and Other Subjects Connected with the Doctrine of Causation. London: John Hatchard and Son.

Secondary sources:

Atherton, Margaret. (1987) 'Berkeley’s Anti-Abstractionism’. In Ernest Sosa (ed.), Essays on the Philosophy of George Berkeley (Holland: D. Reidel Publishing Company). pp. 45-60.

Bolton, Martha Brandt (1987) ‘Berkeley’s Objection to Abstract Ideas and Unconceived Objects'. In Ernest Sosa (ed.), Essays on the Philosophy of George Berkeley (D. Reidel Publishing Company: Holland), pp. 61-84.

Cummins, Phillip D. (1963) 'Perceptual Relativity and Ideas in the Mind'. Philosophy and Phenomenological Research, 24:2, 202-214.

Cummins, Phillip D. (1966) 'Berkeley's Likeness Principle'. Journal of the History of Philosophy 4:1, 63-69.

Cummins, Phillip D. (1990) ‘Berkeley’s Manifest Qualities Thesis'. Journal of the History of Philosophy 28:3, 385-401.

Dicker, Georges. (2011) George Berkeley's Idealism: A Critical Examination Oxford: Oxford University Press.

Hight, Marc A. (ed.) (2013) The Correspondence of George Berkeley Cambridge: Cambridge University Press.

Holden, Thomas. (2019) 'Berkeley on Inconceivability and Impossibility'. Philosophy and Phenomenological Research 98:1, 107-122. 
Jacovides, Michael. (2009) 'How Berkeley Corrupted His Capacity to Conceive'. Philosophia 37, 415-429.

Ott, Walter. (2015) 'Berkeley's Argument for Idealism by Samuel Rickless (review)'. Journal of the History of Philosophy 53: 1, 162-163.

Pappas, George. (1995) 'Berkeleian Idealism and Impossible Performances'. In Robert G. Muehlman (ed.), Berkeley's Metaphysics: Structural, Interpretive, and Critical Essays (Pennsylvania: The Pennsylvania State University Press), pp. 127148.

Pearce, Kenneth L. (forthcoming) 'Berkeley's Theory of Language'. In Samuel Rickless (ed.), The Oxford Handbook of Berkeley (Oxford: Oxford University Press). Rickless, Samuel. (2013) Berkeley's Argument for Idealism. Oxford: Oxford University Press.

Ryan, Todd. (2006) 'A New Account of Berkeley's Likeness Principle'. British Journal for the History of Philosophy 14: 4, 561-580.

Sellars, Wilfred. (1997) Empiricism and the Philosophy of Mind. Cambridge, Massachusetts: Harvard University Press.

Winkler, Kenneth. (1989) Berkeley: An Interpretation. Oxford: Oxford University Press.

Yolton, John. (1985) Perceptual Acquaintance: From Descartes to Reid. Minneapolis: University of Minnesota Press.

Yolton, John. (1996) Perception and Reality: A History From Descartes to Kant. Ithaca and London: Cornell University Press. 